\title{
The Lord Scroop Fallacy
}

\section{Herman E. Stark South Suburban College}

\begin{abstract}
In this paper I identify a fallacy. The fallacy is worth noting for practical and theoretical reasons. First, the rampant occurrences of this fallacy-especially at moments calling for careful thought-indicate that it is more pernicious to clear thinking than many of those found in standard logic texts. Second, the fallacy stands apart from most others in that it contains multiple kinds of logical error (i.e., fallacious and non-fallacious logical errors) that are themselves committed in abnormal ways, and thus it presents a two-tiered challenge to oversimplified accounts of how an argument can go bad.
\end{abstract}

\begin{abstract}
Résumé: J'identifie un sophisme dont on doit prendre note pour des raisons pratique et théorique. Premièrement, sa grande fréquence indique qu'il nuit plus à la bonne rélexion que la plupart des autres sophismes qu'on trouve couramment dans les manuels. Deuxièmement, ce sophisme se distingue de la plupart des autres sophismes par ses multiples types d'erreurs logiques, et par les situations anormales où il se commet. II présente donc deux défis aux explications excessivement simples des erreurs d'un argument.
\end{abstract}

Keywords: Fallacy, logical error, informal logic, critical thinking, self-vitiation, selfreference, interpretative charity.

\section{The Lord Scroop Fallacy}

For your own reasons turn into your bosoms, as dogs upon their masters....

$$
\text { Shakespeare, King Henry } V \text {, II, ii }
$$

Henry V's clever observation concerning self-reference implications captures not only the self-impugned treachery of Lord Scroop and the other conspirators but also the leading theme of this paper, which is the exposure of a fallacy that involves the giving of reasons that, if referred back on themselves, backfire.' To claim "There are no absolutes" with absolute conviction is one example of what I have in mind, but the fallacy I identify herein involves not merely a self-vitiation resulting from self-reference-a phenomenon already confronted in philosophical discussions of, for example, inconsistency and the Liar paradox-but also an 
attack on the worth of thought itself. The fallacy, which I name in memoriam of the memorable way that an assertion backfires in the Lord Scroop scene (such is a philosophical benefit of drama), is rather the more specific logical error of advancing premises that are (unwittingly) self-vitiating in nature for conclusions that are directly anti-thought in tone. Occasions for and occurrences of this seductive and thought-stultifying error are distressingly rampant-indeed, students will leave a Critical Thinking class only to utter instances of the fallacy-and thus what I call the Lord Scroop Fallacy has emerged as singularly treacherous to those perhaps hopeless but nevertheless noble attempts to cultivate a community of thoughtful beings.

\section{The Inside Scoop on Scroop}

I was led to the Scroop fallacy by discovering that some colleagues had made similar observations to mine on the "talk" that we came across in our experience as both students and teachers at universities and colleges, public and private. We observed that certain ubiquitous and at bottom self-refuting platitudes invariably arise in the course of class discussion, in exams and term papers, in the idle talk overheard in the campus corridors, at faculty lunches, in conference presentations given by professional educators, and in meetings with administrators. Certain instances of this talk have been discussed in the history of philosophy (going back at least to Plato's remarks on relativism in the Theaetetus, e.g., 152a-157b), but one finds oneself newly struck by them because of the near-sacrosanct status they have achieved in pop-collegiate culture. Careful attention to what Walton calls the pragmatic aspect of fallacies reveals further that these platitudes are being used as abbreviated proofs for the idea that there is nothing to be justified, discovered, or gained by thinking. ${ }^{2}$ One can even see such talk as taking the form and function of what can be described as a set of Kuhnian "cultural paradigmatic propositions". Uttering the platitudes is taken as a sign that the speaker belongs in the "enlightened" community (i.e., a sign that the speaker has transcended the dusty myth that rational thought is possible and worthwhile). Given all this, I was moved to collect these "dogmas" into a list and then synoptically recognized that many of them are instances of the same fallacy. ${ }^{3}$ Here is a portion of that list (the division into two groups will be explained shortly):

\section{Group I}

1. There is no truth.

2. All generalizations are false.

3. One should not tolerate any intolerance.

4. Words cannot express the truth.

5. There are two sides to every story.

6. All opinions are equal. 
7. All knowledge is based on personal experience.

8. You should think for yourself!

9. Who's to say?

10. Everything is a matter of opinion.

11. All perspectives are true.

12. Nothing is certain.

\section{Group II}

13. There are no absolutes.

14. Everything is relative.

15. Everything changes.

16. Objectivity is impossible.

17. There are no ultimate answers.

I should note at the outset here that not every utterance of the above items constitutes a logical error or fallacy; whether either has been committed depends on a variety of factors, including who makes the assertion and why they make it. I take it that I have not committed a logical error or fallacy by listing the dogmas. The point for now, rather, is that I do not find professional philosophers arguing against bivalence logic in my classes (or at administrative meetings, for that matter), and thus I find myself needing to take class time to explain the fallaciousness of these dogmas (but often letting it slide at administrative meetings). And this is the fact about pop-collegiate culture that I want to underline in this paper. My claim is that these dogmas are hindering -in virtue of their content and not merely qua dogmas - students from entering "the community of sanity." This (ideal) community is guided by the spirit of "critical openmindedness for the sake of truth," and members of it are marked by the recognition that rationally authoritative thought is in some way or other possible. As Putnam puts it:

What is better or what is worse about most questions of human concern is not just a matter of opinion. Recognizing that this is so is the essential price of admission to the community of sanity. ${ }^{5}$

\section{The Dogmas}

I now turn to offering some refutations of the dogmas, i.e., of the more popular avowals of the fallacy. The refutations will be rather quick-I offer a deeper and more charitable analysis later in the paper-but that does not mean that they are not instructive, especially for students (I shall limit my focus to "students" for ease of expression). Indeed, my contention is that most of our contemporary students need to hear these quick refutations if they are ever going to enter the community of sanity; refinements, disputations, and considerations of interpretative charity can come thereafter, and be more incisive as a result. By first focusing on the simple mistakes found in everyday arguments students can be made aware 
that the intellectual insouciance that accompanies their anti-thought attitudes is no longer quite so slick given that they are suddenly unable to defend, much less describe, their conclusions on intellectual life in a non-self-refuting way'.

I put the dogmas in quotation marks to emphasize that students are asserting them as true (and thus to bring out the irony even further). The reason for the two groups is as follows. The fallacy involved with the assertion of these dogmas is the popular logical error of maintaining "worthlessness of thought" conclusions based on assertions that actually imply their own negations. To assert the dogmas, in other words, is actually to assert the opposite of the dogmas. But there are various ways to show the self-refuting nature of such assertions, and thus the distinct groups. Most generally and simply, all of the dogmas can be shown false by considering the proposition true-as those who assert the dogmas would have us believe-and then showing how this assumption implies the negation of the proposition. In addition, the dogmas can be shown to be necessarily false by tracing out the implications from all remaining possibilities, i.e., by showing that assuming the proposition to be false likewise implies the negation of the proposition. The dogmas in Group II, however, can be shown false either in this manner or by employing this method: If dogma $D$ is assumed to be true, and if truth has property $P$, then $D$ ends up false because it denies property $P$, and if dogma $D$ is assumed to be false, then $D$ ends up, again, false. ${ }^{\text {? }}$

\section{Group I}

\section{1. "There is no truth."}

It should be pointed out to students that the sweeping and heady content of this anti-Socratic and pro-Pontius Pilate dogma should not make us quake and quit cognizing, for it is really but a sentence that is, like any other proposition, true or false. And if it is true then we have a truth. And thus to assert the dogma is to refute it. Moreover, if it is false, then it is true that there is truth. Either way and we get truth-every time (ceteris paribus) a non-anti-bivalencing student utters the dogma.

\section{2. "All generalizations are false."}

This dogma perhaps deserves to be so popular given heinous stereotyping. But not really. Some generalizations, e.g., "Memphis summers are humid," after all, are true. And although it can be tricky determining whether something is a generalization or a stereotype, there is a difference. But on to the matter of showing the falsity of this dogma (remembering that most students who utter it are not aware of Russellian-type formal distinctions involving restricted scopes). The claim that all generalizations are false is itself true or false. If the dogma is true, then, being itself a generalization, we have a true generalization. If the dogma is false, on the 
other hand, then that means there is at least one true generalization. Either way the dogma is shown false. ${ }^{8}$

\section{3. "One should not tolerate any intolerance."}

Should one tolerate such an extremist imperative? If the dogma is true, then one should not tolerate the dogma itself. If the dogma is false, then one should tolerate some intolerance (possible example of defensible intolerance: the refusal to tolerate such self-refuting propositions after their exposure). Either way, then, and there is some intolerance that one should tolerate.

\section{4. "Words cannot express the truth."}

A telling response to this assertion is "You don't say?" It may also be useful to note that Plato attacks it fairly directly at 473 of the Republic, and that the power of certain poems, plays, fairy tales and novels to reveal truth suggests that there is truth in words that neither experience nor anything else can express. But sports stars still seem particularly enamored of the underlying idea-e.g., the inevitable "It is undescribable!" (sic) in response to the journalist's equally unimaginative question of "how it feels" to have just won the championship. In such cases it is often best to agree that the sports star may indeed lack the requisite linguistic competency to describe the experience, but also to point out that there is a distinction between "I can" $t$ describe $X$ " and "X is undescribable." But there is no reason to pick on sports stars since the assertion abounds in academia too, e.g., in some presentations of Buddhism or Taoism, and here a koan of sorts can be used as a reply. One should ask if what the professor is telling one (in uttering the assertion) is the truth. If yes, then words can express the truth. If no, then it is false to claim that words can never express the truth, which is to say words can express the truth. Either way, the negation of the dogma ends up as true."

\section{5. "There are two sides to every story."}

This dogma is uttered to express the idea that "enlightened" people "know" that for any position taken there is certain to be a counter-position that is truth-containing. Perhaps many who buy into this dogma are overly-attached to examples involving car accidents, the soothing words of apparently omniscient marriage counselors, or even Aesop's fable "The Man and the Lion." But even in the case of car accidents it is possible and indeed often actual that there is "just one side to the story," and just because the dogma is roundly taken to be an a priori truth-as are the other dogmas-does not prove that it is a priori or even true.

If it is true that there are two truth-containing sides to every story, then there is another truth-containing side to the dogma itself. This truth-containing other side to the dogma is this: "There are not (at least) two sides to every story," or, more precisely, "There is just one truth-containing side to some stories." In other words, 
if the dogma is true, then it is true that some stories have only one side and hence the dogma is false. On the other hand, if the dogma is false, then again we are left committed to the truth of the proposition that asserts some stories as having but one side. Either way, i.e., if there is or is not another side to the dogma, one ends up with the negation of the dogma as being true. ${ }^{10}$

\section{6. "All opinions are equal."}

If this dogma is taken in a certain way then it could make sense, for the class of opinion is epistemically inferior to the class of knowledge (see Plato's Divided Line analogy in the Republic, 509d-511e), and so when viewed from the latter class the assertion may be true. If no student knows the color of my car, then no pure opinion would stand out, ceteris paribus, as authoritative compared to the others, and all the guesses would be of equal epistemic unimportance. But the problem is that the dogma is not intended in this literal sense but rather taken to mean that all declarative sentences are of equal epistemic weight. To assert the dogma, in other words, is to declare that no declarative sentence is a case of knowledge. The dogma, understood in this non-literal way, is self-impugning, and its falsity can be shown as follows. The dogma is either true or false. If it is false, then we have this claim as true: "Not all opinions are equal." If the dogma is true, then all opinions, including the opinion opposite to the dogma, are true. That opposite opinion is this: "Not all opinions are equal." Either way and the negation of the dogma is true.

\section{7. "All knowledge is based on personal experience."}

This dogma would invalidate the possibility of learning something worthwhile in a lecture, from a book, or through thought. Moreover, do we really have to jump off the top of the Sears Tower to know what will happen below? The dogma is asserted to be an item of knowledge, but if so is it based on personal experience? If no, then not all knowledge is based on personal experience. If yes, then on what experience could it possibly be based? It would seem none, for what experience can put one into contact with "all knowledge?" And it would be an odd move in the context of this dogma to try to get to "all knowledge" by making inferences to what has not been personally experienced. The upshot, then, is that to claim that the dogma is itself an item of knowledge leads to the conclusion that not all knowledge is based on personal experience.

As an aside (an aside that shows the ethical dimensions of informal logic), this is a particularly harmful instance of the Scroop fallacy because of the student lives that have been scarred by its gullery."

\section{8. "You should think for yourself?"}

Many who consider themselves champions of critical thinking champion this dogma. They devoutly teach that one shouldn't just do what others do and think what 
others think but rather that one should think for oneself. But if this dogma is true then one shouldn't pay any attention to it!

To be less pithy (which is hard to resist in a paper like this), the irony is that when students "hear and believe" this dogma they are most often not being "independent" at all but rather robotically doing what others tell them to do. More often than not, in other words, students end up oblivious to the fact that as they charge forth from class unto the world, proclaiming "I think for myself," they have become nothing other than mindless mimics of the dogma.

Another line of criticism is to note that the formulation of the dogma is itself thoughtless. A lamentable linguistic fad nowadays is to use really overstated phrases as if the proper word alone is impotent. The dogma displays this same thoughtless instinct with its inclusion of the words 'for yourself' after 'think'. The word 'think' is enough! It is thoughtless to demand that students think for themselves; one should rather demand that they think.

To put things in yet another way, this dogma is either true or false. If it is false that you should think for yourself, then one should do the opposite of the dogma, which is apparently just thinking. If the dogma is true, then one should do the opposite of the dogma, viz., think. Either way, one should not follow the order to think for oneself-but one should think.

\section{9. "Who's to say?"}

This rhetorical question is the favorite new excuse to stop thinking. Those who smugly toss it out at every juncture are in fact utterly lost in abstraction, for they are forgetting the fact that despite occasional misfires we do fly planes, perform surgery, prescribe eyeglass strengths, and correctly conjugate foreign verbs. My favorite rejoinder to it is "I am," but less flashy is "Whoever has the best reasons." And if a student is quick enough on the uptake to fire back with "Who's to say who has the best reasons?", then it is often effective to point out again the fact that we do perform symphonies, utilize CAT-scans, build skyscrapers, identify fallacies, and leave classrooms through doorways instead of through the wall, and that this indicates that there already is rational authority, and that indeed we often identify such authority in terms of training, knowledge, reliability, or relevant experience.

A self-referential refutation is as follows. "Who's to say?" most often really means "No one can speak with rational authority about matter X." But the student, in advancing this claim, is attempting to speak with rational authority about matter $\mathrm{X}$ ! By claiming that no one can speak with authority about matter $\mathrm{X}$ the student is thereby attempting to make a rationally authoritative claim about matter X. It should be noted that this error of obliviously helping oneself to a God's-eye perspective from which to issue forth sweeping proclamations-whether or not the proclamation is at the same time the denial of such a vantage point-is a bit of recurring hubris in both the history of philosophy and the other Scroop-instantiating dog- 
mas. ${ }^{12}$ The best rejoinder to one who pushes this dogma, then, is "Who are you to say 'Who's to say?'?"

\section{0. "Everything is a matter of opinion."}

Is it a matter of opinion that everything is a matter of opinion? If no, then not everything is a matter of opinion. If yes, then what is being asserted is that it is not a matter of opinion that something may not be a matter of opinion. Either way, we end up with something that is not a matter of opinion.

\section{1. "All perspectives are true."}

This dogma has special appeal for students reading (or misreading, if it be possible) Nietzsche's Der Wille zur Macht. But if the dogma is false, then not all perspectives are true. If it is true, then this perspective is also true: not all perspectives are true, i.e., some perspectives are not true. Either way, we end up with a perspective that is not true.

\section{2. "Nothing is certain."}

Is that certain? If yes, then something is certain. If no, then it is not certain that nothing is certain, i.e., the possibility of something certain is certain. Either way, we end up with something certain.

\section{Group II}

Each of the dogmas in this group will be refuted by two different methods. The general method (hereinafter "GM"), as seen above, assumes the propositions to be true and then draws out the implication that the proposition is therefore false, and then adds on to this by tracing how the assumption that the proposition is false leads to the same implication. The other method requires the auxiliary recognition that truth is absolute, nonrelative, immutable, objective, and ultimate. The characteristics of truth method (hereinafter "CTM"), in other words, requires a direct appeal to the characteristics of the "classic" concept of truth in order to generate a refutation.

As a brief aside, why should one grant the auxiliary assumption that CTM requires? Some students will question, in other words, why it should be granted that truth is absolute, nonrelative, immutable, objective, and ultimate. One useful reply - for the students, though perhaps not for the professional philosopher theorizing on truth-is to hit the following points. First, what kind of answer does the student want? A nonabsolute, relative, mutable, subjective and nonultimate one? Second, does the student have any reason for maintaining that truth does not have these characteristics-i.e., a reason more plausible than the standard conclusions invalidly drawn from the mundane recognition that different people have differing 
opinions? (This is not ad ignorantiam because of the next remark). Third, is the student aware of-much less able to refute--the arguments that philosophers and others have offered in support of these classic characterizations of truth? ${ }^{13}$ Socrates" "doubling the square" example in the Meno and Augustine's observation that seven and three were, are, and will be ten (allowing that middle-sized objects are being added in base 10), for example, should at least be pondered before making any final rejection of the auxiliary assumption. ${ }^{4}$ But even if one is of a withholding disposition with regard to the classic characteristics of truth, the following dogmas are still refutable by GM.

\section{3. "There are no absolutes."}

Students utter this dogma with absolute conviction. But one should be perplexed when they ardently attempt to convince one of its truth. Is it absolute that there are no absolutes? If yes, then there is an absolute. If no, then the dogma has neither bark nor bite and the assertion of it is merely shorthand for "It is not absolute that there are no absolutes," which is itself ironically tantamount to the claim that the very possibility of there being an absolute is itself an absolute possibility. Either way we get something absolute. Here is the CTM refutation:

The dogma "There are no absolutes" is either true or false. If it is true then we have an absolute (given that truth is absolute). If it is false then we have an absolute.

\section{4. "Everything is relative."}

This dogma is really just a different formulation of the "Nothing is absolute" dogma. The smarter students-usually disdainful of their colleagues-tend to prefer this version because they think it has an Einstein-like flavor to it. ${ }^{15}$ But like the other formulation this one is also demonstrably false, and indeed in two ways. GM goes as follows. If everything is relative, one has to wonder, then isn't it relative that everything is relative? If no, then we have something nonrelative. If yes, then "It is relative that everything is relative" is what is being asserted, but that just asserts the non-relative possibility that something is nonrelative. Either way we get something nonrelative. CTM runs as follows:

If the dogma is true then we have something nonrelative (given that truth is nonrelative). If the dogma is false then we also have something nonrelative.

\section{5. "Everything changes."}

The quickest response to this dogma is to ask what the sum of two apples and three apples is today. It is also instructive to point out that assertions such as "Hildegard is wearing a red sweater" are incomplete, elliptical, or time-bound. But GM would have us ask this question: Does the dogma itself change? If no, then 
not everything changes. If yes, then into what does it change? Into what can it change? Presumably into this only: not everything changes. Either way, whether or not the dogma is itself included under everything, to assert the dogma is to assert that not everything changes. CTM is as follows:

If the dogma is true then there is something that does not change (given that truth is immutable). If the dogma is false then something does not change. ${ }^{16}$

\section{6. "Objectivity is impossible."}

Is this dogma itself objective? If it is, then we have something objective, which of course entails the weaker claim that objectivity is possible. If, on the other hand, the dogma is not objective, e.g., if it is subjective (or intersubjective) that objectivity is impossible, then we have the objective possibility that objectivity is possible. Either way and we have something objective. The CTM analysis of this dogma is this:

If the dogma is true then we have something objective (given that truth is objective). If the dogma is false then it is true that there is objectivity.

\section{7. "There are no ultimate answers."}

This dogma has been around for a long time and has been sanctioned by many a reputable sage. ${ }^{17}$ It means that ultimately there are no ultimates. But this, of course, is confounding. Is not this dogma itself expressed as an ultimate answer? It is, and hence by asserting the dogma one falsifies it. And even if it weren't ultimate, then the dogma would in fact be this claim: it is not ultimate that there are no ultimate answers, which is ironically tantamount to the claim that there is an ultimate possibility that there are ultimate answers. Either way we get something ultimate. The CTM analysis is as follows:

The dogma is true or false. If it is false, then it is true that there are ultimate answers. If the dogma is true, then there are ultimate answers (given that truth is ultimate).

\section{What Precisely is Wrong with Scroop?}

One reason for identifying the Scroop fallacy is that it is more pernicious to clear thinking than many of the fallacies found in standard logic texts. A second reason for identifying it is more theoretical in nature. The Scroop fallacy stands apart from most others in that it contains multiple kinds of logical error (i.e., fallacious and non-fallacious logical errors) that are themselves committed in abnormal ways, and thus it presents a two-tiered challenge to oversimplified accounts of how an argument can go bad.

The standard logic text will state that an argument can go bad by containing either a false premise or a mistake in reasoning. It states further that the latter flaw 
is of peculiar interest to the logician whereas the former is not since the determination of truth values is (usually) an empirical matter. This description is in keeping with the soundness/validity distinction. But the Scroop fallacy does not fall cleanly into this description.

First, the falsity of the Scroop premises is not an empirical matter but indeed a logical one. It is a logical error, though not a fallacy, to assert certain propositions. As such the Scroop premises are indeed of peculiar interest to the logician.

Second, the logical falsity of the Scroop premises is too peculiar to be adequately covered by those exception-admitting footnotes mentioning contradictions as premises, for the Scroop premises are sui generis in that they combine features of both contradictions and paradoxes. Falsity due to self-reference implications is sufficiently different than falsity due to asserting a straightforward $p \& \sim p$, whereas the necessary falsity of the Scroop premises makes them sufficiently different than the "true if false and false if true" feature of paradoxes. It thus seems that there are different kinds of logical error worth noting within the already neglected class of logical errors in assertion.

Third, the reason Scroop is a fallacy is not simply because it is something that contains a logical error. It is one thing to advance assertions that are self-vitiating, and another to base anti-thought conclusions on such assertions. Scroop, as introduced above, is the attempt to do the latter, and this is what makes it a fallacy. Scroop is a failure in argumentation. An explicit definition is useful at this point:

The Lord Scroop Fallacy: The logical error of advancing premises that are (unwittingly) self-vitiating in nature for conclusions that are directly anti-thought in tone.

This definition, by the way, rules out the Liar paradox and other sorts of nonanti-thought albeit self-vitiating propositions as instances of Scroop premises (the Liar paradox, for example, is a problem for thought, not an attack on the worth of thought), but the main point is that Scroop is not reducible to the error of asserting self-vitiating propositions. The mere presence of a logical error in something does not entail the presence of a fallacious argument, and Scroop underlines this oftignored theoretical point.

Fourth, the texts identify "mistakes in reasoning" as the specific kind of logical error that would make Scroop a fallacy, but Scroop does not involve a mistake in reasoning; i.e., the inferences from the Scroop premises to the Scroop anti-thought conclusion are valid. It is not merely that the dogmas, if true, imply anti-thought conclusions, but rather more convincingly that any inference from a necessarily false premise is valid. And so if an account of fallacies does not recognize any other kind of logical error in argument than mistakes in reasoning, then Scroop is not a fallacy. 
But it seems that an account of fallacies should recognize logical errors in argumentation that extend beyond that of mistakes in reasoning. Petitio principii, for example, involves no invalid inference ( $p$ implies $p$ ), and can furthermore involve neither empirical nor logical errors in assertion, but it still fails as an attempt to provide support for a conclusion. ${ }^{18}$ Scroop is also a failure in argumentation, and this failure also cannot be accounted for in terms of an invalid inference. The upshot is that Scroop joins the ranks of the lonely petitio, making it less easy to downplay the anomalous petitio in order to preserve a uniform definition of fallacy. Moreover, Scroop and petitio conjunctively support (though perhaps the former even more than the latter) the idea that the class of logical errors in argument extends beyond mistakes in reasoning. And even if one balks at this suggestion it is still the case that Scroop forces one to clarify in extraordinary detail just why or why not something is classifiable as a fallacy or indeed a logical error.

What precisely is wrong with Scroop? We have seen that this question is theoretically instructive because there are numerous things wrong with Scroop and isolating them serves to delineate and underline various conceptual aspects of argumentation and remind us of the odd ways that they can be instantiated.

\section{Charity and Scroop}

Why does Shakespeare's Henry $V$ expose the Scroop conspiracy in the subtle manner he does? Is he bent on humiliating his enemies, or on maximizing his revenge by drawing out the inquisition? Something else? In any event, Henry does seem to go all out to make the conspirators eat their earlier words against mercy. And this is what he accomplishes, but with an extraordinary twist. Henry is a Christian monarch and-if we are to accept Dostoevski's "problem of educating a prince" reading of the Henry $I V$ plays-a man profoundly aware of the existential importance of learning and teaching. And thus the twist: through Henry's manner of dealing with the conspirators they come to regret qua repent their harsh words against mercy.

Henry, with respect to the conspirators, exercises charity at its most profound, for he understood them in terms of humans worthy of confronting a truth previously and harmfully missed. Following this lead-in both method and outcomeI now will apply the principle of charity to the Scroop fallacy. ${ }^{19}$

Applying the principle of interpretative charity to the Scroop fallacy would seem, at first glance, to give us this: most instances of the Scroop fallacy are but overstatements. What is really meant by most of those who assert the dogmas, in other words, is that the scope of thought is severely limited because most generalizations are false, few absolutes exist, objectivity is largely impossible, etc. But a problem with this more charitable interpretation, a problem stressed in this essay, is that it does not account for the stultification of thought and the range of intellectual insouciance exhibited by many of those who utter the dogmas. Too many 
students, in other words, cannot be understood as thoughtfully defending an intellectually plausible relativism. There may be a weird consistency about using thoughtless premises to defend anti-thought conclusions, but such argumentation still does not qualify as thoughtful. Furthermore, the use of sloppy formulations concerning fundamental matters is grossly thoughtless (to adapt Socrates' remonstration of Thrasymachus at $344 \mathrm{e}$ of the Republic). These problems are too interdictive for this first way of applying the principle of charity to the Scroop fallacy, and so I suggest a second.

A truer albeit darker way of applying charity to Scroop would have us understand the widespread and automatic instances of the fallacy as more of a communal rather than individual failing. The widespread instances of the Scroop fallacy are symptoms of the general distortion of an intellectual virtue--'thoughtful openmindedness"--into vice-"failure to exercise critical thought". The perfidious nature of the Scroop fallacy thus lies in the bitter irony that this anti-thought fallacy has actually been encouraged by the push for inculcating "open-minded" attitudes in students. As is the case with many other sound sentiments, it is the sad fate of the schola for authentic open-mindedness to have been transposed by dogmatic dissemination into a wearisome recitative. The evil of close-mindednessas opposed to its epistemological ill-effect of hindering the pursuit of truth-is that it does nothing to hinder human inertia in its slide towards the robotic and therefore towards the banality of evil. And this is what has happened in the case of the Scroop fallacy. The prevalence of certain Scroop-instantiating chants among students, e.g., "Everything is a matter of opinion," is evidence enough that the virtue of "critical open-mindedness for the sake of truth" has been misappropriated by pop-collegiate culture, and Logic/Critical Thinking instructors may be partly to blame because of their failure to check occurrences of the Lord Scroop Fallacy. ${ }^{20}$

\section{Notes}

1 Lord Scroop had counseled King Henry, in preceding moments of the play, against being merciful to a man caught railing against King Henry, and so now Scroop, who has just been exposed to all those present as a participant in a plot against Henry, finds himself rather tongue-tied when it comes to begging for mercy. Scroop's claim (that mercy should not be granted to those who commit crimes against the king) thus backfires on Scroop, i.e., on the speaker and not on the claim itself, and so is slightly different than the fallacy discussed in this paper, but the main analogy-the backfire lesson-still holds.

2 For "Logical Pragmatics" see D. Walton, Informal Logic: A Handbook for Critical Argumentation (Cambridge: Cambridge University Press, 1989).

${ }^{3}$ It has been suggested to me that I should refer to instances of the fallacy not as dogmas but rather as maxims, slogans or dicta because the propositions are not actually believed, e.g., students do not "really" mean them, or at least not in an exceptionless way. But don't they? Determining belief is a tricky matter. Students 
do, to be sure, exit classrooms via the doorway rather than by attempting to go through brick walls, and thus their behavior bespeaks some belief in objective truth, but on the other hand they are rendered intellectually paralyzed in philosophical discussion by their robotic expostulations of the propositions, and thus this indicates a "real" sense in which they (sometimes) believe them, or think they believe them.

${ }^{4}$ This warning against the seemingly obvious pitfalls of abstracting language from context continues to be missed both in and out of professional philosophy (probably due in part to the mantra-chanting proclivities of humankind). In the present day, for example, the mere use of certain words is taken to be "insensitive"; such a Fahrenheit 451 mentality misses the fact that whether an insensitive remark has occurred depends on context (perhaps someone has mispronounced, or is struggling to learn English, or is listing for others those words that are usually taken to be insensitive).

"Hilary Putnam, "Why is a Philosopher?", in Realism with a Human Face, ed. J. Conant (Cambridge: Harvard University Press, 1990), 114.

${ }^{6}$ My position is thus a counter-or perhaps better a supplement-to Fisher's emphasis on theoretical arguments as "real arguments". See A. Fisher, The Logic of Real Arguments (Cambridge: Cambridge University Press, 1998).. Along these lines, but opposite with respect to truth value and more complicated with respect to analysis, is Ray Sorenson's discussion of propositions whose utterance guarantees their truth (apart from 'I exist'). He offers 'I believe some claims that are necessarily false' as such an example, noting that anyone who tries to correct him by claiming that it is not possible to believe what is impossible is conceding that he believes a false proposition-which in this case is a proposition (Sorenson claims) that is necessarily false. R. Sorenson, American Philosophical Quarterly, vol. 33, no. 3, July 1996, 247.

The explicitly formal presentation here of these rather simple techniques should be considered in light of J.J.C. Smart's remarks in Chapter 1 of Philosophy and Scientific Realism about philosophers being fitted to eliminate nonsense, the desirability of some technique for recognizing non-obvious nonsense, and the application of such a technique as being at least a part of philosophy.

* There are different kinds of generalization, and some of them are true even if there are exceptions. A ceteris paribus generalization, for example, is not shown false merely by pointing out an exception.

"Consider also that Alfred de Musset tells us that "II vaut mieux faire que dire" (Pierre et Camille, ch. 2).

10 For an extended discussion of the "two sides" dogma, see Trudy Govier, "Are There Two sides to Every Question?" in Trudy Govier, ed., Selected Issues in Logic and Communication (Belmont, CA: Wadsworth, 1988).

${ }^{11}$ Another aside is that those who push this dogma are victims of a mediocre view of human cognitive abilities; they fail to recognize that some humans can learn from other people's experiences.

${ }^{12}$ Consider, in light of the point just made, the following attack on the possibility of objective truth: "The falsity of our past ideas indicates that our current ideas are not true either." If so, then we have indication that this idea is itself false. 
${ }^{13}$ It should be noted that the explications of the individual characteristics is a separate matter and a burden shared by those who deny that truth should be so described.

${ }^{14} \mathrm{My}$ parenthetical qualifier (by Augustine's arithmetic example) is included to highlight both the contextual nature of the evaluation of reasoning and the fact that contextuality does not detract from universality. For Augustine's example, see On Free Choice of the Will, trans. B. Hackstaff (New York: MacMillan Co., 1964), 2.7.82-83. Apropos Augustine, the suggestion in this paper that the role of the informal logician includes the observing of and concern for the thoughtful community is somewhat reminiscent of the motives and circumstances surrounding Augustine's The City of God.

${ }^{15}$ Relativity theory, of course, does not endorse the claim that everything is relative. To set matters straight (geodesically speaking), what is "relative" in relativity theory are the descriptions of specific events. But that which is crucial for knowledge, e.g., the laws of nature, is not relative.

${ }^{16}$ This dogma reminds me of the following prediction about the stock market that I have found in every personal finance book that I have read: "The stock market will remain unpredictable."

${ }^{17}$ Including Bertrand Russell in his The Problems of Philosophy (Oxford: Oxford University Press, 1959), 161: "...no definite answers [to philosophical questions] can, as a rule, be known to be true". That sounds pretty definite and pretty definite to me.

${ }^{18}$ For an analysis of the further idea that not all circular reasoning is vicious, see $\mathrm{H}$. Brown, "Circular Justifications", in PSA, vol. 1, 1994, 406-414.

"The truth that Henry's tactic makes manifest to the conspirators, by the way, should not be articulated as a moral imperative (as is the simplistic fashion), e.g." "One should be merciful", but rather in terms of something like "the existential realization of how an act of mercy can bespeak the worth of graciousness".

${ }^{20}$ Anything worthwhile in this essay is dedicated to Michael Degnan. 1 am gratefully indebted, if that not be a contradiction in terms, to the following for their sharp criticisms and comments on earlier, even worse versions of this essay: Michael Degnan, Michael Gelven, James Hardy, Tomis Kapitan, Mitch Haney, Hal Brown, members of an APA audience, and anonymous reviewers for Informal Logic.

Herman E. Stark Department of Humanities South Suburban College 15800 S. State Street South Holland, IL 60473 U.S.A hermanestark@yahoo.com 